\title{
Frequency and procedure of management of unidentified corpses admitted to the mortuary of the hubert koutoukou maga university teaching hospital of cotonou
}

\section{ADOVOEKPE Jean Marie, BIGOT Cedric Egnonwa Parfait ${ }^{2, *}$, YAYI Aristide ${ }^{3}$, ADJIBODE Omer ${ }^{4}$, AGBOBLI Yawo Apelete ${ }^{5}$}

\author{
1,2,5 Assistant Professor, ${ }^{3,4} \mathrm{MD},{ }^{1,3,4}$ University of Parakou, ${ }^{2}$ Unit of Forensic Medicine, Faculty of Heath Science, University of \\ Abomey, Calavi, ${ }^{5}$ University of Lome, Benin
}

*Corresponding Author:

Email: bigot.ce@gmail.com

\begin{abstract}
Introduction: Corpse identification is a major concern in forensic medicine. This study aimed to determine the frequency of cases of unidentified corpse discovery in the city of Cotonou and describe the procedure related to their judicial management.

Material and Methods: This research work was a case control study conducted in the largest public funeral home in the city of Cotonou. Data were analyzed using the software Epi-info.

Results: During the time period of study, unidentified corpses accounted for $1.27 \%$ of the dead bodies admitted to the funeral home. In $70.4 \%$ of cases, corpses were those of men. To identify corpses, a judicial inquiry was initiated in $51.5 \%$ of cases. Only $8.8 \%$ of corpses were officially sealed and only $3.0 \%$ of corpses underwent a forensic autopsy.

Conclusion: Those results suggest that very little has been done to enable the restitution of mortal remains to families.
\end{abstract}

Keywords: Unknown dead body, Medical identification, Forensic autopsy.

\section{Introduction}

Every year, thousands of people die without being identified. Unless identified, their mortal remains are not handed over to their family. They are eventually buried in anonymity. Those corpses are registered in funeral homes and forensic medicine institutes as " $\mathrm{x}$ " or unidentified corpses in French-speaking countries or "John Deo" and "Jane Doe" in English speaking countries.

In the United States, a study carried out from 1979 to 2004 reported a frequency of 28.5 cases per 10 million inhabitants. $^{1}$ In India, unidentified or non-requested corpses of individual accounted for nearly $16 \%$ of corpses examined in forensic funeral homes. ${ }^{2}$ In Ibadan, those corpses accounted for $21,4 \%$ of the ones sent to the Department of Anatomy. ${ }^{3}$

The discovery of an unidentified corpse inevitably leads to the opening of a judicial inquiry. The purpose of the inquiry is to enable collection of information necessary for the identification of the deceased and determine the cause of death. Most of the information is collected in the course of forensic autopsy.

There is no official estimation of the phenomenon frequency in Benin. But in most cases, unidentified corpses of persons discovered in the city of Cotonou are sent on a priority basis to the funeral home of Hubert Koutoukou Maga National University Teaching Hospital (CNHU-HKM). Therefore, this study was initiated to determine the frequency of $\mathrm{X}$ or unidentified corpses and identify the procedure related to their judicial management.

\section{Material and Methods}

The study was conducted in the CNHU-HKM funeral home in Cotonou. This mortuary serves at the same time as a funeral care center and a municipal mortuary. It receives corpses of people dead in the CNHU-HKM and outside.

This research work was a case control study focused and carried out over a five-year period running from January 1, 2008 to December 31, 2012. Study target population consisted of dead bodies deposited in the CNHU-HKM funeral home during the period of study. We included all the corpses of people registered as unidentified, as their families did not claim them till the day of their burial by the municipal environment and hygiene office by decision of the public prosecutor/district attorney at the magistrates' court of Cotonou.

The variables investigated by the study were related to anthropometric characteristics, circumstances of corpse discovery as well as forensic procedures performed before interment.

Substantive data were retrieved from registers of admission to CNHU-HKM funeral home, and medical examination forms.

The software Epi Info version 3.5.4 was used for the entry, analysis and processing of data. Statistical results were expressed as averages or percentages.

The study was authorized by the Minister of Internal Affairs, Public Security and Decentralization and by Director of CNHU-HKM/Cotonou. We made sure that medical confidentiality and court-ordered secrecy are complied with.

\section{Results}

During the period of study, 10,356 corpses were kept and spent some time in the CNHU-HKM funeral home. Among them, 521 corpses were reported as abandoned. In addition, there were 132 corpses registered as unidentified i.e. a frequency of $1.27 \%$ (Fig. 1). 
Male corpses accounted $70.4 \%$ of cases and sex ratio was equal to 2.9. They were all above 20 years old. 40-60 years age group was predominant with 92 cases (Table 1). They were also 8 newborns.

Sixty-four corpses were registered as violent deaths i.e. a frequency of $48.5 \%$. (Table 2) shows corpse distribution according to manner of death. Accidental deaths are predominant. They account for $51.35 \%$ of violent deaths. Most of them are deaths following road traffic accidents $(n=31)$. The remaining accidental deaths were associated with drowning.

There were 18 deaths considered as homicides or murders i.e. a frequency estimated at $28.1 \%$. There were 3 cases of lynching, 3 cases of deaths occurred after blows delivered by means of blunt objects, 5 cases of stab wounds and 8 cases of strangulation. Suicides $(n=2)$ involved exclusively male subjects. Hanging was the method of suicide used in the two (02) cases.

Judicial inquiry was initiated in 68 cases i.e. $51.5 \%$. Only 6 corpses $(8.8 \%)$ were officially sealed and only 4 corpses experienced an autopsy during the inquiry. There was no fingerprinting on corpses; all the same, no genetic material was collected. Corpses were buried by the municipal environment and hygiene office in mass graves.

\section{Discussion}

The city of Cotonou has three (03) public funeral homes and one private funeral home. This case control study was conducted in the largest one, the one which receives and attends a higher number of corpses likely to cause forensic problems. The said study points out that corpses unidentified or registered as $\mathrm{X}$ dead bodies account for $1.27 \%$ of all the corpses admitted to the CNHU-HKM funeral home.

Higher frequencies were observed in studies conducted in Côte d'Ivoire, ${ }^{4}$ France $^{5}$ and India. ${ }^{2}$ The authors of those studies have reported respective frequencies estimated at $6.9 \%, 9.1 \%$ and $10 \%$. The said studies were carried out in funeral homes with forensic specialty. There is no forensic funeral home in Cotonou. Besides, in most cases of discovery of dead body of unidentified people, corpses were systematically handled and managed by the municipal environment and hygiene office and buried without further ado. In developed countries, unidentified corpses generally pass through forensic institutes to undergo a forensic autopsy. ${ }^{4,6,7}$

The corpses of unidentified persons are mostly men and adults (age between 20 and 60 years). This observation agrees with the remarks of Chatto padhyay ${ }^{8}$ who noted in his cohort from Calcutta that $87 \%$ of subjects are men and that $71.3 \%$ of subjects belong to the group of people whose age oscillates between 31 and 60 years.

The city of Cotonou is the economic capital of Benin. It enjoys a relative stability and attracts the youth living in most economically disadvantaged cities. Those young people move to cities where they have no connection. This situation is also observed in New Delhi in India ${ }^{2}$ where unidentified corpses are mostly those of people considered as "homeless" who arrive in town further to rural migration. For Andreev, ${ }^{9}$ homeless people and those living in town without any connection are more at risk of not being identified at the time of death. The research works conducted by Paulozzi ${ }^{1}$ in the United States have pointed out that the black African group, although it represents a minority among the American population, was the most affected by unidentified death (46.5\% of cases). According to Heninger, ${ }^{10}$ this remark may be associated with a very high exposure of black population to hazards and vicissitudes of life.

This study also highlights that very few resources are used to identify corpses. Police investigations are initiated only in half of cases. Forensic autopsy intervenes only in $2.9 \%$ of cases. Obviously, the management of those corpses is not consistent with the American, ${ }^{11}$ European $^{12}$ and African $^{13}$ community-based recommendations concerning management of unidentified corpses. For instance, those recommendations suggest the performance of autopsy in all cases of obvious or suspicious non-natural death, no matter the timeframe existing between the event responsible for death and death itself, and regardless of the dead body condition, particularly when it is an unidentified person. ${ }^{12}$ The purpose of autopsy is to identify the cause of death but also to provide indications likely to help identify the deceased.

Visual identification is the first method of identification of unidentified corpses. It proved to be effective in $72 \%$ of cases in the cohort of Cattaneo. ${ }^{6}$ Corpses may also be identified on the basis of their morphological features, results of dental examination, fingerprints or DNA profiling. Taken separately, those methods help identify corpses in 10 to $25 \%$ of cases. However, they generate less errors. ${ }^{5}$

The absence of national data base, which may enable recording and matching of ante and post-mortem data on the deceased, is also a barrier and obstacle to the identification of those corpses.

Table 1: Age wise distribution of unidentified body

\begin{tabular}{|c|c|c|c|c|}
\hline Age group (in year) & $\begin{array}{c}\text { Males } \\
(\mathbf{n = 9 8})\end{array}$ & $\begin{array}{c}\text { Females } \\
(\mathbf{n = 3 4 )}\end{array}$ & $\begin{array}{c}\text { Number } \\
\text { of cases }\end{array}$ & $\begin{array}{c}\% \text { of total } \\
\text { number of cases }\end{array}$ \\
\hline $0-20$ & 2 & 6 & 8 & 6,1 \\
\hline $21-40$ & 74 & 18 & 92 & 69,7 \\
\hline $41-60$ & 22 & 10 & 32 & 24,2 \\
\hline
\end{tabular}


Table 2 : Causes of violent death distribution of unidentified body

\begin{tabular}{|l|c|c|c|c|}
\hline Manner of death & $\begin{array}{c}\text { Males } \\
(\mathbf{n = 5 2})\end{array}$ & $\begin{array}{c}\text { Females } \\
(\mathbf{n = 1 2})\end{array}$ & $\begin{array}{c}\text { Number of } \\
\text { cases (n=64) }\end{array}$ & $\begin{array}{c}\text { \% of total } \\
\text { number of cases }\end{array}$ \\
\hline Suicide & 2 & 0 & 2 & 3,1 \\
\hline Accident & 25 & 9 & 34 & 53,1 \\
\hline Homicide & 15 & 3 & 18 & 28,1 \\
\hline Légal action & 10 & 0 & 10 & 15,6 \\
\hline
\end{tabular}

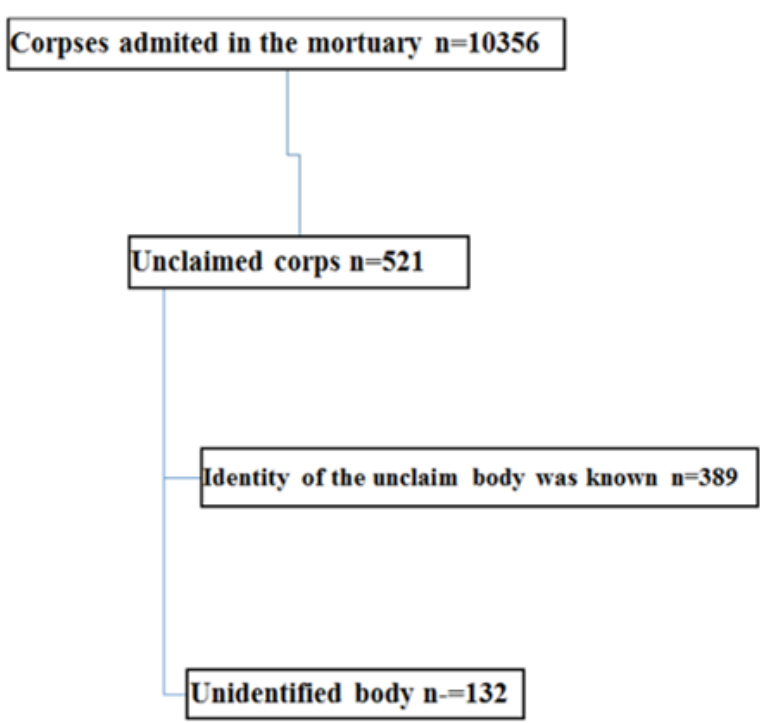

Fig. 1 Coprs selection process

\section{Conclusion}

This study has highlighted that unidentified corpses found in Cotonou are mostly those of young male subjects dead further to a road traffic accident. Unfortunately, they do not receive the attention they deserve.

\section{References}

1. Paulozzi LJ, Cox CS, Williams DD, Nolte KB. John and Jane Doe: the epidemiology of unidentified decedents. $J$ Forensic Sci 2008;53(4): 922-27.

2. Yadav A, Kumar A, Swain R, Gupta SK. Five-year study of unidentified/unclaimed and unknown deaths brought for medicolegal autopsy at Premier Hospital in New Delhi, India. Med Sci Law 2017;57(1):33-8.

3. Osuagwu F, Imosemi I, Oladejo O. Sources of cadaver used for dissection at the Ibadan Medical School, Nigeria: Analysis of a three-year data. Afr J Biomedical Res 2004;7:93-5.

4. Kacy A. Morts sous X: quelle a été la prise en charge Médico-légale et Socio-judiciaire à Abidjan de 2002 à 2009 Abidjan ;. Université FHB Abdijan Cocody; 2012.

5. Cavard S, Alvarez JC, De Mazancourt P, Tilotta F, Brousseau P, de la Grandmaison GL, et al. Forensic and police identification of " $\mathrm{X}$ " bodies. A 6-years French experience. Forensic Sci Int 2011; 204(1-3): 139-143.

6. Cattaneo C, Porta D, De Angelis D, Gibelli D, Poppa P, Grandi M. Unidentified bodies and human remains: An Italian glimpse through a European problem. Forensic Sci Int 2010;195(1-3):167.e1-167.e6.

7. Kumar S, Verma AK, Ali W, Singh US. Homeless and unclaimed persons' deaths in north India (Jan 2008-Nov 2012): a retrospective study. Med Sci Law 2015;55(1):11-5.

8. Chattopadhyay S, Shee B, Sukul B. Unidentified bodies in autopsy - A disaster in disguise. Egypt J Forensic Sciences. 2013;3(4): 112-115.

9. Andreev E, Pridemore WA, Shkolnikov VM, Antonova OI. An investigation of the growing number of deaths of unidentified people in Russia. Eur J Public Health 2008;18(3):252-57.

10. Heninger M, Hanzlick R. Nonnatural deaths of adolescents and teenagers: Fulton County, Georgia, 19852004. Am J Forensic Med Pathol 2008;29(3):208-13.

11. Randall BB, Fierro MF, Froede RC. Practice guideline for forensic pathology. Members of the Forensic Pathology Committee, College of American Pathologists. Arch Pathol Laboratory Med 1998;122(12):1056-64.

12. Conseil de l'Europe. Recommandation R (99)3 About forensic autopsy rule Harmonisation. Feb 2, 1999.

13. African Socciety of Forencis Medicine. Minimum standards fo forensic medicine practice in Africa. 1st ed. Ibadan: ASFM Secretariat; 2015. 78 p. 